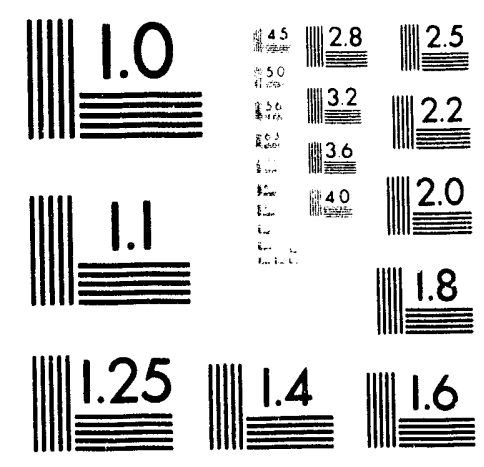



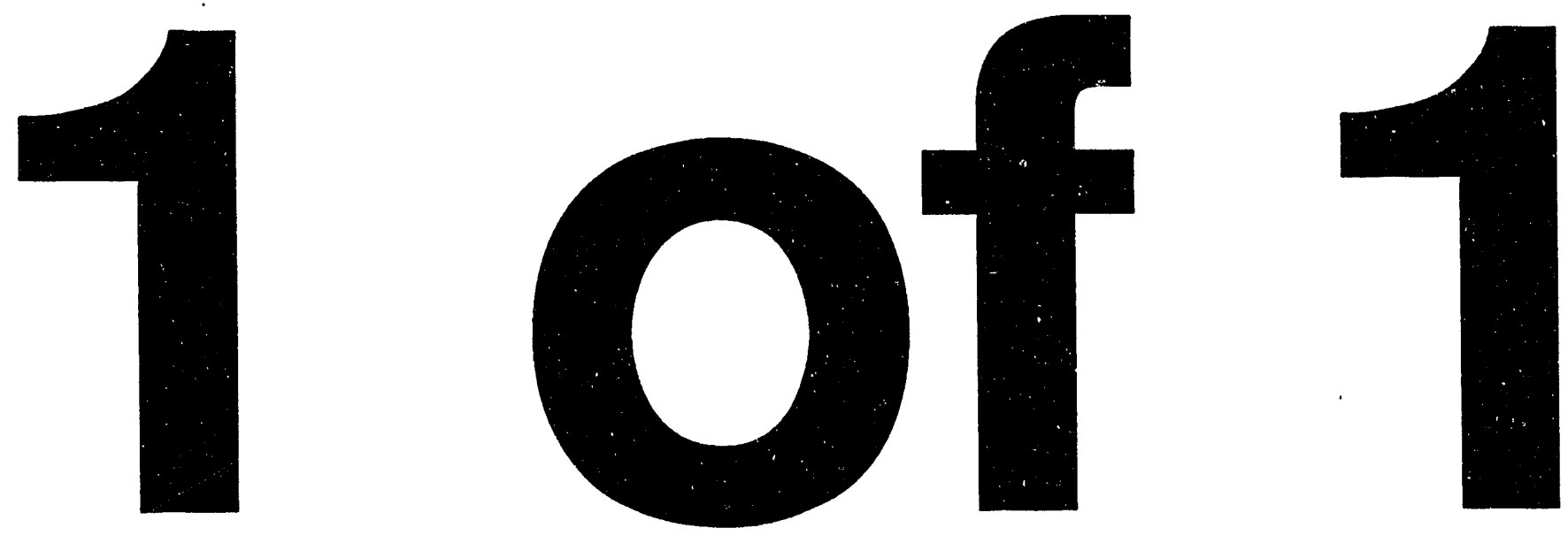


\title{
R\&D of a Prototype SSC 80-K Synchrotron Radiation Liner System in a Half-Cell of 4-K Magnets*
}

\author{
Q.-S. Shu, W. Chou, and D. Clark, et al. \\ Superconducting Super Collider Laboratory ${ }^{\dagger}$ \\ 2550 Beckleymeade Ave. \\ Dallas, TX 75237
}

July 1993

\footnotetext{
"To be presented at the International Cryogenics Engineering Conference, July 12-14, Albuquerque, N.M. †Operated by the Universities Research Association, Inc., for the U.S. Department of Energy under Contract No. DE-AC35-89ER40486.
}

\section{MASTER}




\title{
R\&D OF A PROTOTYPE SSC 80-K SYNCHROTRON RADIATION LINER SYSTEM IN A HALF-CELL OF 4-K MAGNETS*
}

\author{
Q.-S. Shu, W. Chou, D. Clark, W. Clay, Y. Goren, R. Kersevan, \\ V. Kovachev, P. Kraushaar, K. Leung, J. Maddocks, D. Martin, \\ D. Meyer, R. Mihelic, G. Morale, C.Ruiz. G. Snitchler, M. Tuli, \\ W. Tumer, L. Walling, K. Yu, and J. Zbasnik \\ Superconducting Super Collider Laboratery ${ }^{\dagger}$ \\ 2550 Beckleymeade Ave. \\ Dallas, TX 75237-3997 USA
}

\begin{abstract}
This paper reports on the efforts that have led to the development of a viable design for an SSC 80K Synchrotron Radiation Liner System. The liner is one method under consideration to minimize the presence of photodesorbed gases in the particle beam line vacuum, thereby assuring acceptable operational availability of the SSC Collider. The 80K liner is also aimed at improving the Collider's cryogenic thermal efficiency, which would allow a potential luminosity upgrade. Trade studies, engineering analyses, concept evaluation, and design are introduced. This paper also briefly discusses the preliminary consideration of lower-temperature ( $20 \mathrm{~K}$ and $4 \mathrm{~K})$ liners.
\end{abstract}

\section{INTRODUCTION}

The SSC Collider is the first proton superconducting accelerator designed to operate at an energy of $20 \mathrm{TeV}$ (each beam) and a beam current of $72 \mathrm{~mA}$. The Collider will produce a synchrotron power of $0.14 \mathrm{~W} / \mathrm{m}$ and a total of $18 \mathrm{~kW}$ into $4.2 \mathrm{~K}$ for the two rings. This radiated power may trigger a serious impact of photodesorbed gases on the operational availability of the Collider. The interaction between beam particle and photodesorbed gases may greatly reduce the beam lifetime, and the scattered beam power may lead to quenching of the superconducting magnets. Collider availability may be unacceptable if this concern is not addressed. ${ }^{1}$ The liner is one method under consideration to minimize the presence of photodesorbed gases in the particle beam line vacuum. Secondly, the liner is aimed at improving the Collider's cryogenic thermal efficiency, which would allow a potential luminosity upgrade. The ultimate goal is to require no more than one machine warm-up per year for vacuum maintenance during operation of the SSC Collider.

A liner is a piece of scientific art and technical architecture that presents the challenge of developing a system inside the existing particle beam tubes that directly interfaces with the synchrotron light and compensates for the synchrotron by-products of photodesorbed gases and heat. The system addresses photodesorption, the particle beam, magnet fields, beam-induced wakefields, the RF system, the cryogenic system, magnet quench conditions-especially quench-induced Lorentz pressure-and many other interdisciplinary technical problems that must be considere ${ }^{2}$ and resolved in a timely manner. One of the challenges to the liner design is that there is no experience from which to draw directly. There is also a schedule challenge in that the liner design must catch up with many years of magnet design efforts.

\footnotetext{
"To be submitted at the 1993 Cryogenic Engineering Conference Advances in Cryogenic Engineering, July 12-16, 1993, Albuquerque, NM.

†perated by the Universities Research Association, Inc., for the U.S. Department of Energy, under Contract No. DE-AC35-89ER40486.
} 
The liner's required operational temperature of $80 \mathrm{~K}$ was based on analyses from the photodesorption data available from the CDG and SCDG measurements at the time when the ASST liner design had heen performed. ${ }^{3}$ In the case of an $80 \mathrm{~K}$ liner, there is a second purpose, namely, to replace the $4 \mathrm{~K}$ dynamic heat load of the synchrotron radiation with a static heat load, independent of the beam intensity, and to transfer the intercepted heat to the liquid nitrogen system. This has the advantage of upgrading the Collider luminosity over the lower-temperature liners with a higher thermal dynamic coefficient.

This development program was accomplished in two major phases: (1) concept proposal and evaluation, and (2) concept selection and design. The first-phase effort was summarized in the "Report on the ASST II Liner Status" in November 1992 (SSCL-N805). 4 The second-phase effort will be documented in the "SSC $80 \mathrm{~K}$ Synchrotron Radiation Liner Design Report" in July 1993 (SSCL-N-818).

However, the recent photodesorption coefficient experimental data indicate the viability of $4 \mathrm{~K}$ and $20 \mathrm{~K}$ systems, which were previously considered as not viable using the old CDG and SCDG measurements. An extensive trade study and analysis have also been performed since May 1993 to investigate the possibility of developing a $4 \mathrm{~K}$ liner system for the SSC Collider. Progress on the $80 \mathrm{~K}$ liner system has also greatly facilitated evaluation of the $4 \mathrm{~K}$ and $20 \mathrm{~K}$ liner systems.

\section{K ASST LINER CONFIGURATION}

The liner system will be installed into all the superconducting dipole magnets, quadrupole magnets, and spool pieces in the arc region of the Collider if such a system is determined to be the best method to address the concern of synchrotron radiation and the consequent photodesorbed gases. The first liner system was developed and tested in the Accelerator System String Test (ASST) facility, since the ASST is basic unit of the SSC Collider.

Figure 1 is a simplified schematic of the $80 \mathrm{~K}$ liner system prototype installed in a halfcell of the ASST. The liner system consists of an $80 \mathrm{~K}$ perforated tube (the liner tube) located coaxially inside the $4.2 \mathrm{~K}$ magnet bore tube. An $80 \mathrm{~K}$, high-pressure GHe loop of $0.25 \mathrm{~g} / \mathrm{s}$ is used to maintain the dipole magnet liner temperature around $80 \mathrm{~K}$; the GHe flow is then recooled by $\mathrm{LN}_{2}$ in the $\mathrm{LN} 2$ cooling pipe of a dipole magnet. A special endconducting cooling structure is designed to cool the quadrupole magnet liner, since the ASST quadrupole beam tube ID $(32.3 \mathrm{~mm})$ is much smaller than an ASST dipole ID $(42.3 \mathrm{~mm}){ }^{5,6}$ The end-cooling approach allows liners with a maximum uniform ID of $25.3 \mathrm{~mm}$ to pass through the magnets' beam tubes with different IDS. A thin layer of the cryosorber $(0.5 \mathrm{~mm})$ is pasted on the inner surface of the $4.2 \mathrm{~K}$ beam tube to pump the photodesorbed gases through the holes on the liner tube. The size and pattern of the holes on the liner tube are designed to meet both the requirement of pumping speed of photodesorbed gases and the requirement of the RF impedance.

The low thermal conductivity supports are designed to keep the liner tube in the magnet centerline. The $80 \mathrm{~K}$ liner configuration also requires that the magnet interconnect allow a pathway for the $80 \mathrm{~K}$ cooling tubes into the beam vacuum environment and also provide access to the RF joint and the good thermal contact joint for assembly and maintenance. This interconnect is now called the cryogenic box. The thermal expansion and $\mathrm{RF}$ joints located in the cryogenic box between magnets are structured to assure the continuity of image current induced by the charged particle beams in the Collider beam tube. ${ }^{6}$ These structures also take care of the different thermal contractions among magnets, liners, and Spool Pieces. However, the liner is discontinuous as routed through the Beam Position Monitor (BPM). An interface design of the $80 \mathrm{~K}$ liner with the BPM has been conducted, and the interface will be installed with the BPM between the Spool Piece and the quadrupole magnet. ${ }^{7}$ The liner cooling loop in the Spool Piece is specially arranged to pass liner cooling pipe through the Spool Piece vacuum barrier that separates the magnet insulation vacuums between half-cells of the magnet string. 

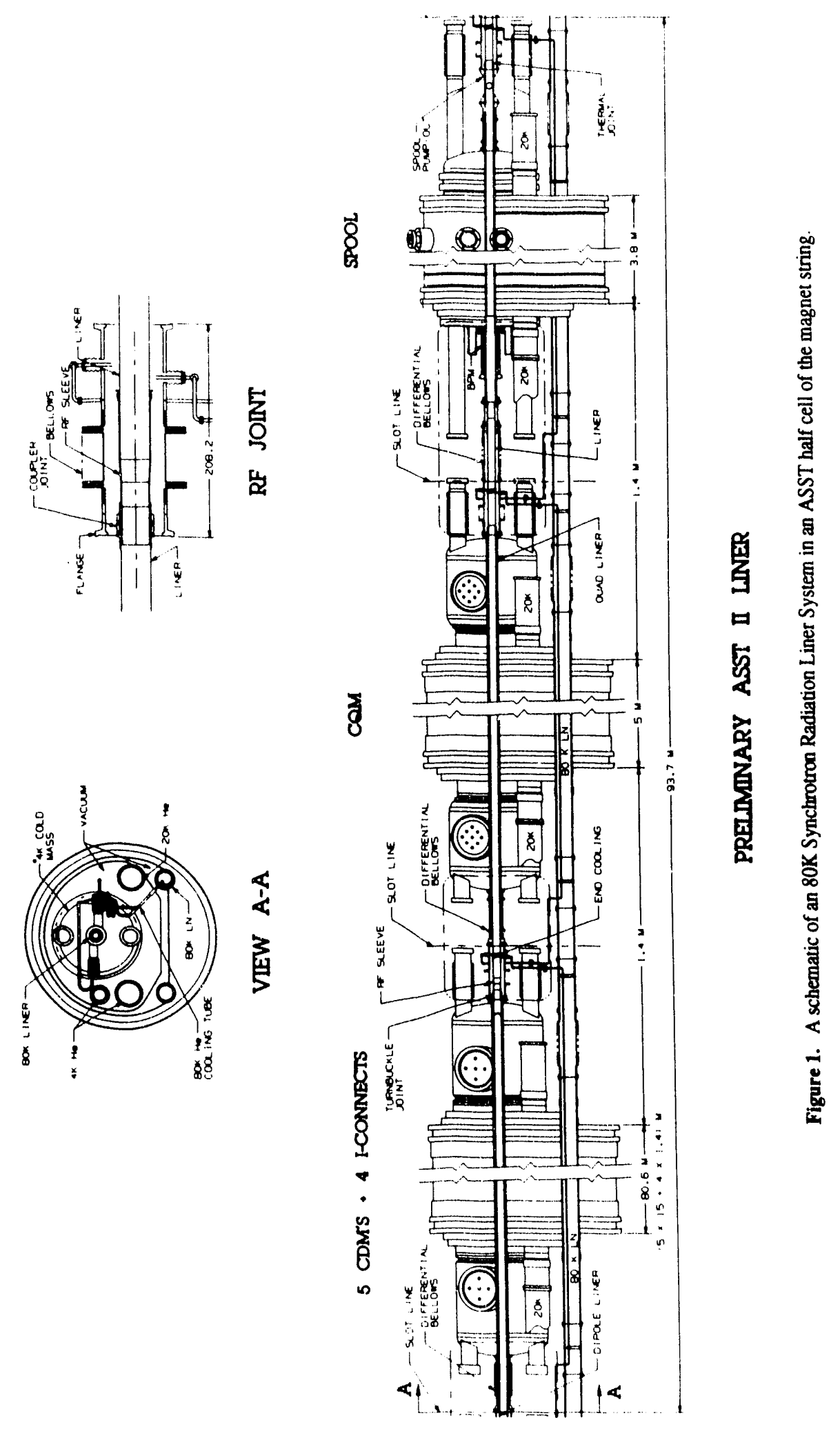


\section{DESIGN ANAI,YSES AND CONCEPTS SELECTION}

In order to minimize the cost and schedule impact and to remove or reduce the risks that a liner design can impact the Collider operation, trade studies, physics and engineering analyses, and concepts selection have been carried out.

It is desirable to have the maximum pessible and uniform liner ID due to (1) particle beam commissioning, (2) particle beam dynamic stability, and (3) safety margin of impedance. However, the maximum liner ID is constrained by (1) the available magnet beam tube ID, and (2) the minimum liner radial space. Using a regular cooling approach, minimum liner radial space needs $6 \mathrm{~mm}$; using end-conducting cooling, the radial space needs $3.5 \mathrm{~mm}$. Tables 1 and 2 show the maximum liner ID $^{4}$ and the liner impedances ${ }^{8}$ of various options.

Table 2 shows that the use of slots on the liner instead of holes reduces the impedance of the liner tube, but not enough to lower the total impedance significantly, since this is dominated by the liner ID. The possible approaches to increase the safety margin include: (1) increasing the threshold impeciance (e.g., a larger longitudinal emittance, a higher RF voltage at injection of the Collider, etc.); or (2) reducing the machine impedance (e.g., a larger liner diameter, an optimization in size and shape of the hole geometry, etc.)

In the design, the liner tube shall also meet the requirements set forth in Table 3.

Table 1. Possible maximum liner ID in various cases.

\begin{tabular}{lcccccc}
\hline & Dipole & Magnet & Quzad & Magnet & Spool & liece \\
\hline Object & Beam tube ID, & I.iner ID & Beam tube & Liner ID & Bean tube & Liner ID \\
& $\mathrm{mm}$ & $\mathrm{mm}$ & ID, $\mathrm{mm}$ & $\mathrm{mm}$ & ID, $\mathrm{mm}$ & $\mathrm{mm}$ \\
ASST & 42.3 & 25.3 & 32.3 & 25.3 & 32.3 & 25.3 \\
(iD), B \& W & 32.3 & 20.2 & 32.3 & 20.2 & 32.3 & 20.3 \\
Desired & 42.3 & 31 & 42.3 & 31 & 42.3 & 31 \\
\hline
\end{tabular}

Table 2. Comparison of impedances

\begin{tabular}{ccccccc}
\hline Case & $\begin{array}{c}\text { Liner } \\
\text { ID, } \mathrm{mm}\end{array}$ & $\begin{array}{c}\text { Hote/Slots } \\
\text { Coverage }\end{array}$ & $\begin{array}{c}\text { Z(liner) } \\
\mathrm{M} \Omega / \mathrm{m}\end{array}$ & $\begin{array}{c}\text { \% (other) } \\
\mathrm{M} \Omega / \mathrm{m}\end{array}$ & $\begin{array}{c}\text { Z (total) } \\
\mathrm{M} \Omega / \mathrm{m}\end{array}$ & $\begin{array}{c}\text { Safety } \\
\text { margin }\end{array}$ \\
\hline Baseline & 32.3 & & & 40 & 40 & 6.7 \\
With liner & 25.3 & $2 \mathrm{~mm}, 2 \%$ & 22 & 112 & 133 & 2 \\
With liner & 25.3 & $2 \mathrm{~mm}, 4 \%$ & 44 & 112 & 156 & 1.7 \\
With liner & 25.3 & $2 \times 6,2 \%$ & 8 & 112 & 120 & 2.2 \\
With liner & 33 & $2 \mathrm{~mm}, 4 \%$ & 15 & 40 & 55 & 4.9 \\
\hline
\end{tabular}

Table 3. Liner tube requirements.

\begin{tabular}{|c|c|}
\hline $\begin{array}{l}\text { Inner wall conductivity and thickness } \\
\text { Liner impedance }\end{array}$ & $\begin{array}{l}\sigma^{*} \delta>2 \times 10^{5} \Omega^{-1} \\
Z \mathrm{I} / \mathrm{n}<0.34 \Omega \\
7 . \mathrm{t}<20 \mathrm{M} \Omega^{/ \mathrm{m}}\end{array}$ \\
\hline Inner wall photodesorption coefficient & $\begin{array}{l}\eta=0.02 \\
\alpha=0.3 \text { for } \mathrm{H}_{2}\end{array}$ \\
\hline Liner pump speed & $6(0) \mathrm{l} / \mathrm{m} / \mathrm{s}$ for $\mathrm{H}_{2}$ \\
\hline Total liner heat leak to $4 \mathrm{~K}$ & $<1 \mathrm{~W}$ for dipole \\
\hline (ryosorher pump speed & $12\left(00-3(x) \mathrm{l}\left(\mathrm{m} / \mathrm{s}\right.\right.$ for $\mathrm{H}_{2}$ \\
\hline ('ryourber pumping capacity & 30 Thorr $\mathrm{l} / \mathrm{m}$ at $294 \mathrm{~K}$ \\
\hline (ryosorter activation temperature & $\begin{array}{l}294 \mathrm{~K} ; \text { regeneration }<80 \mathrm{~K} \quad 112,<194 \mathrm{~K} \text { all } \\
\text { gases; recovery fraction regencration }>98 \%\end{array}$ \\
\hline I. iner quench survivability and ASMI: code & $I(X)$ quenches in $2.5 \mathrm{yr}$ \\
\hline Radiation dose lolerance & $14(0)$ Mrad in $25 \mathrm{yr}$ \\
\hline
\end{tabular}

\section{ASST DIPOLE MAGNET LINER}

Figure 2(a) is the cross section of a dipole magnet liner tube having the same aperture as the quadrupole liner of $25.3 \mathrm{~mm}$ ID. A copper thickness of $0.5 \mathrm{~mm}$ is required for the conductive wall. To undertake the Lorenty force, which cannot be ignored in a dipole magnel, a 0.75 -mm-thick stainless steel shell is used to meet strength requirements. A $2-\mathrm{mm}$ hole is adopled for pumping, and $1.3(0)$ holes/m are required. Figure $2(\mathrm{~b})$ is the ASST dipole liner tube. The cooling tube is sized to allow $0.25 \mathrm{~g} / \mathrm{s}$ flow with an inlet pressure of 365 psi to provide flow to 48 half-cells connected in series." The $\Delta T$ across one dipole liner is $-2 \mathrm{~K}$ at $1(1)^{3.3}$ baseline luminosity and $\sim 6 \mathrm{~K}$ at $1(1)^{34}$ upgraded. The GHe 
entering L.e flow iube is brazed on the liner tube to keep good heat exchange with the liner tube, and the returning GHe flow tube is mechanically attached to the liner tube to maintain a poor thermal contact. Figure 2(c) shows the ASST dipole magnet assembly.

(a)

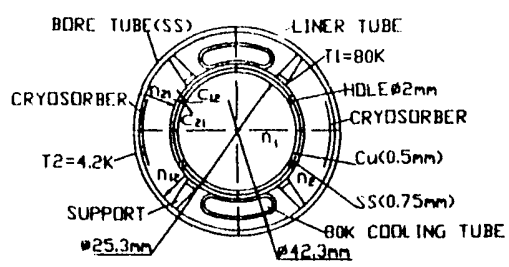

(b)

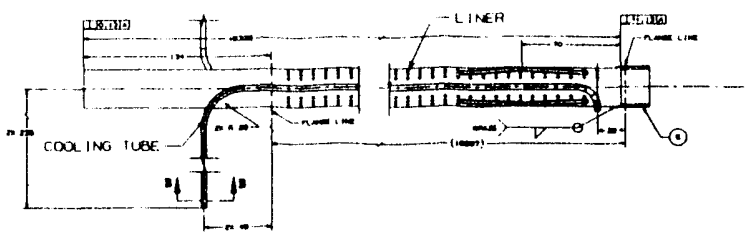

(c)

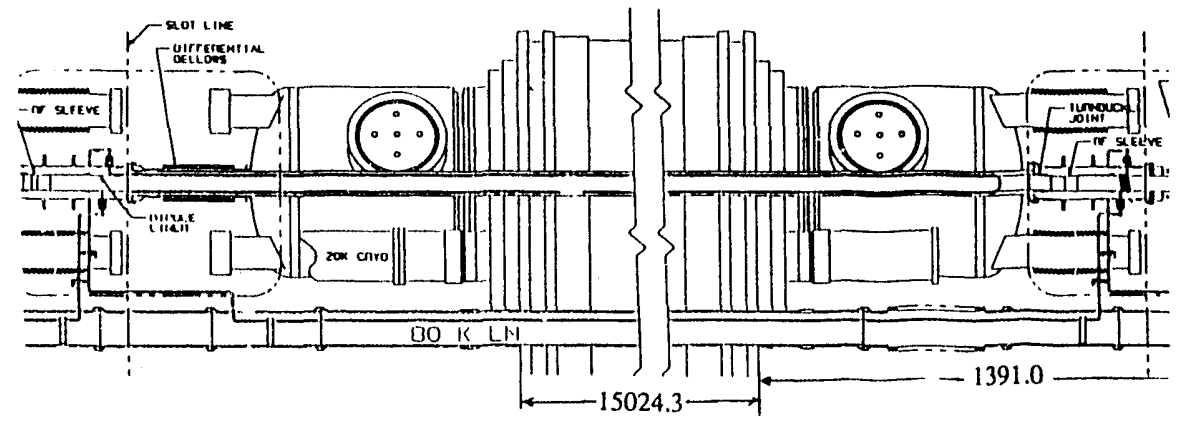

Figure 2. (a). A cross section of the 80K ASST dipole magnet liner tube; (b) an 80K ASST dipole liner tube and its support; (c) the dipole liner assembly.

\section{ASST QUADRUPOLE MAGNET LINER}

Figure 3(a) is a cross section of an ASST quadrupole (CQM) magnet liner tube with a limiting aperture in the A.SST system (25.3 mm ID). The end cooling has been adopted for the ASST quadrupole liner, as shown in Figure 3(b). The liner tube is 1-mm-thick copper, and the support will be either Vespel pegs or ceramic spheres. The conductive wall requirement is satisfied locally if $\mathrm{T}<110 \mathrm{~K}$. According to a calculation, a $1.5-\mathrm{mm}$-diameter hole is efficient and requires 2800 holes $/ \mathrm{m}$. The radial space of $1.5 \mathrm{~mm}$ is required between liner OD and cryosorber for acceptable backscatter of gas molecules. The quench-induced Lorentz force and resultant stress were found to be very low, so a stainless steel support layer outside the copper tube is not needed. Figure 4 shows the temperature distribution along an end-cooling quadrupole liner tube.

(a)

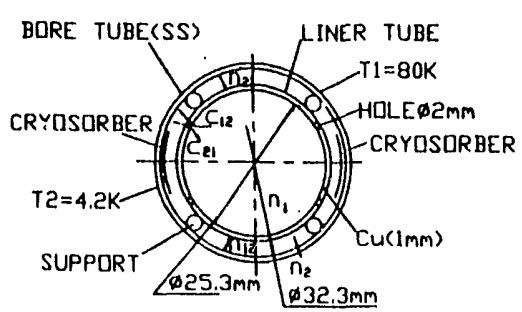

(b)

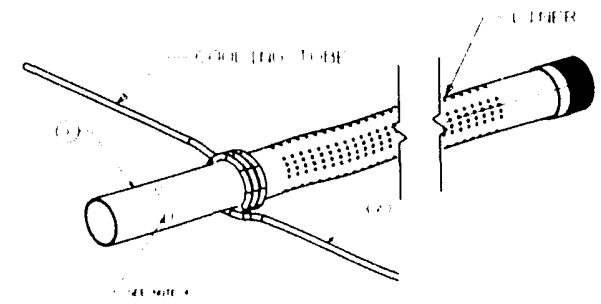

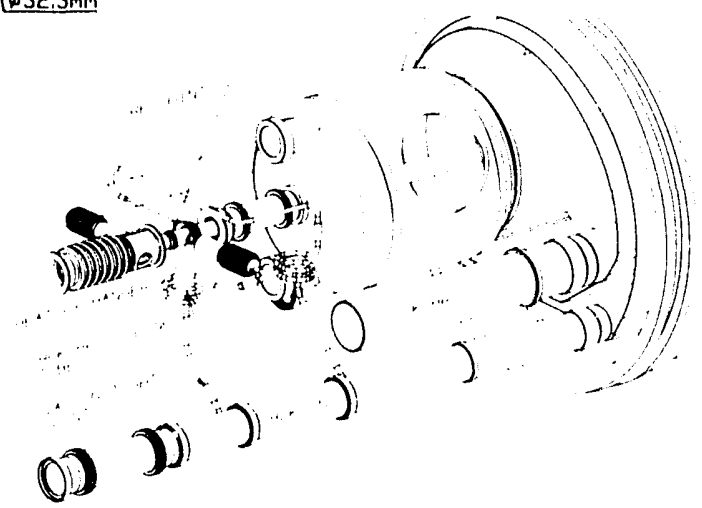

(c)

Figure 3. (a). A cross section of the $80 \mathrm{~K}$ ASST quadrupole liner tube; (b) an $80 \mathrm{~K}$ ASST quadrupole liner tube; (c) with end-conducting cooling. 


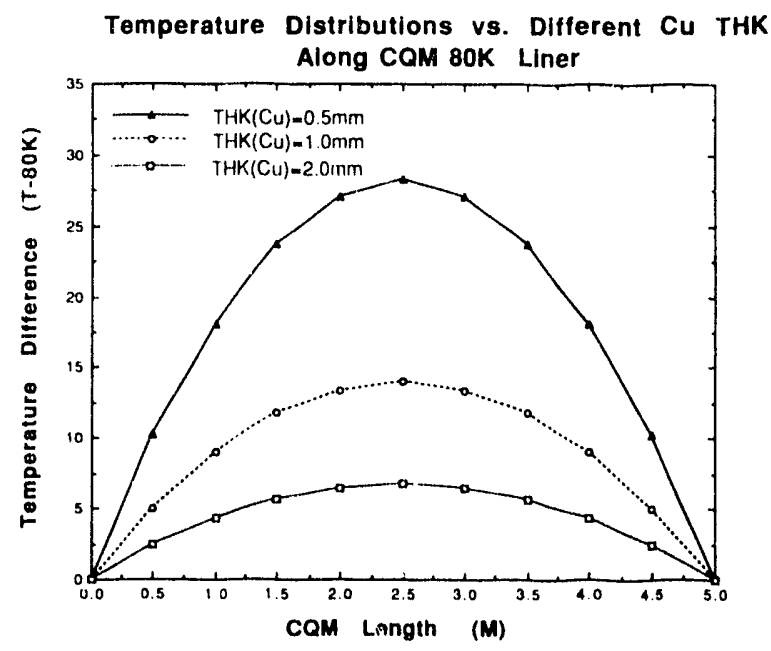

Figure 4. The temperature profile along the CQM liner with end-conducting cooling.

\section{INTERCONNECT REGION, BPM, AND SPOOL PIECE}

The $80 \mathrm{~K}$ liner design requires that the magnet interconnect allow a pathway for the $80 \mathrm{~K}$ cooling tubes into the beam vacuum environment. The liner has an RF joint, but the beam tube does not. Also, the liner has a good thermal contact joint for assembly and maintenance. This interconnect for the liner is known as the cryogenic box. ${ }^{10}$ Inside this cryogenic box are housed the good thermal contact joint, the RF joint, and the "magic joint." Figure 5 shows a quadrupole cryobox assembly with the right side connecting to the BPM and the spool piece. ${ }^{11-13}$

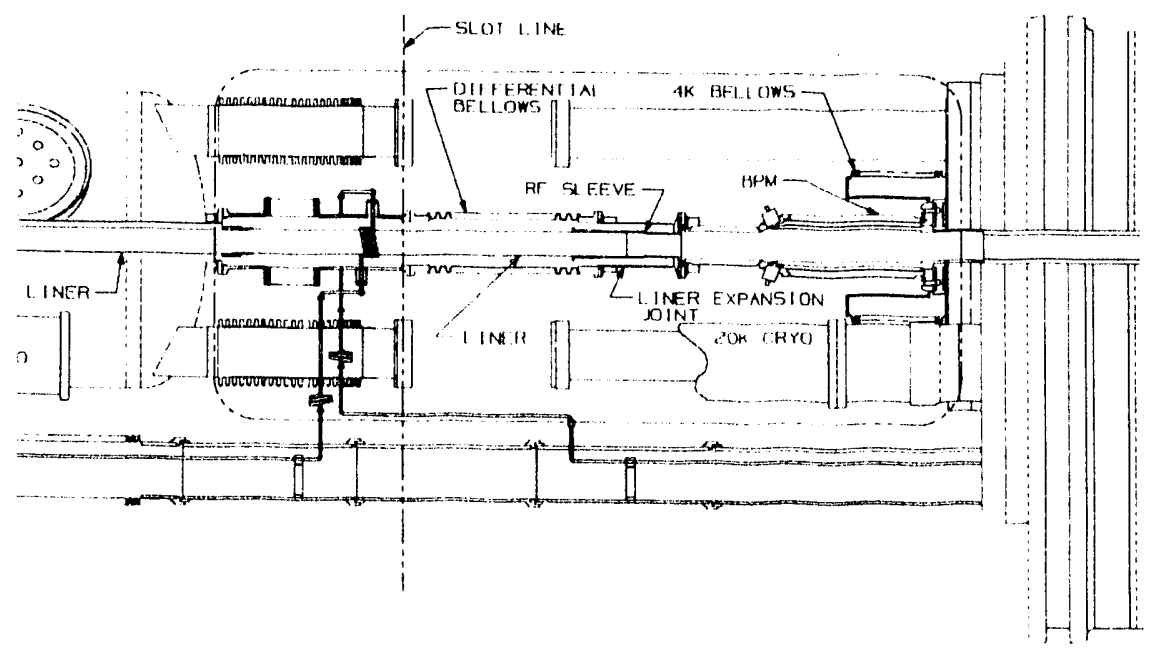

Figure 5. The interconnect between a $\mathrm{CQM}$ liner and spool piece.

A beam tube bellows assembly connects the beam tube flanges at the lead end and return end of adjacent magnets. This bellows assembly was modified to allow the cooling tubes access into the vacuum environment inside of the assembly. The beam tube bellows assembly is at $4 \mathrm{~K}$, and the cooling tubes are at $80 \mathrm{~K}$. To minimize the heat transfer from the cooling tubes to the beam tube bellows, the cryogenic box requires some thermal standoffs to increase the thermal path.

Since the magnets are cooled $t$ om room temperature to a working temperature of $4 \mathrm{~K}$, a $51-\mathrm{mm}$ thermal contraction is produced in the magnets. The cryogenic box is designed $\mathrm{t})$ allow for this thermal contraction. The good thermal contact joint is used to connect sections of the quadrupole magnet. F F tlexible refers to a sleeve that is used to connect adjacent liner tubes.

The conceptual design of the BPM with the interface and the spool piece liner was conducted by D. Martin and D. Clark. ${ }^{11,12}$ The problem they faced was how to maintain 
the system performance of the BPM while incorporating changes in cryogenic design. The BPM system electrical centerline-to-sextupole magnetic axis must be less than $0.1 \mathrm{~mm}$. The BPM detector should have long-term mechanical stability and reliability. Additional heat leaks should he maintained below the $2(1)$ - $\mathrm{mW}$ to $4 \mathrm{~K}$ budget. RF continuity for image currents, good RF transitions, and impedance b. low $50 \mu \Omega$ should be maintained.

In order to simplify the interface structure of a BPM with an $80 \mathrm{~K}$ liner, an $80 \mathrm{~K}$ BPM has been developed, as shown in Figure 6(a). However, reducing the heat leak from the $80 \mathrm{~K}$ BPM to the $4 \mathrm{~K}$ part of the spool piece becomes a big concern. A polyimide insulator was used to thermally separate the $80 \mathrm{~K} \mathrm{BPM}$ from the $4 \mathrm{~K}$ spool piece. To keep the required ultrahigh vacuum, a shield was utilized to separate the beam vacuum and the thermal insulation vacuum. A bellows was placed in the shield, and a $20 \mathrm{~K}$ thermal bridge was designed to intercept the heat from $80 \mathrm{~K}$ to $4 \mathrm{~K}$.

If a $4 \mathrm{~K}$ BPM is used, the $80 \mathrm{~K}$ liner end conductive cooling becomes more complicated, as shown in Figure 6. To reduce the heat leak through the copper liner tube from $80 \mathrm{~K}$ to the $4 \mathrm{~K}$ BPM, a 10-20-cm-long piece of stainless steel tube is inserted between the BPM and the copper liner tube. The synchrotron radiation, the heat leak from the liner to the BPM, the heat leak from the liner to the $4 \mathrm{~K}$ beam tube, and the heat exchange between the liner and the $80 \mathrm{~K}$ GHe must meet the law of conservation of energy. Figure 7 shows the temperature distribution of the liner.
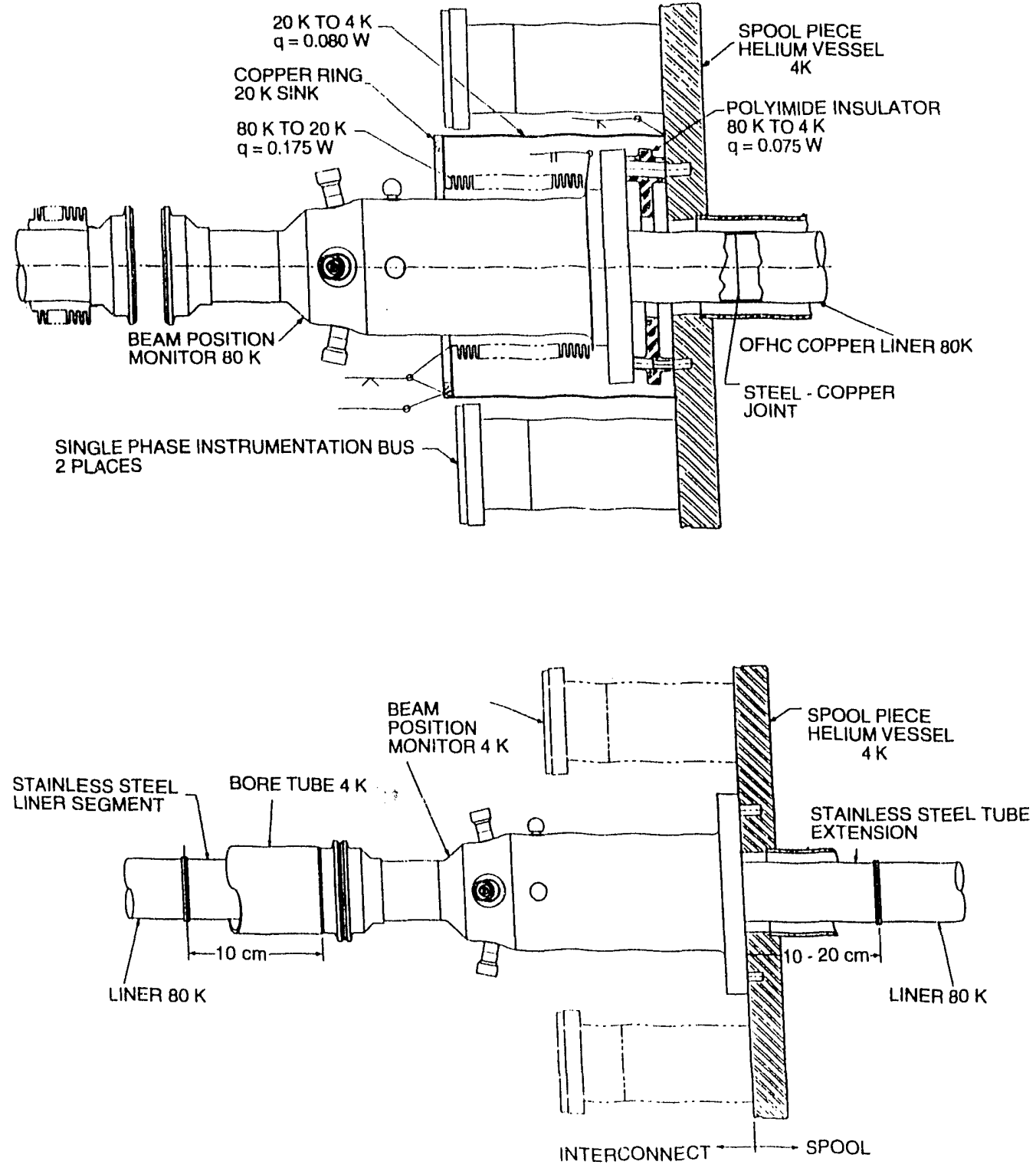

Figure 6. $80 \mathrm{~K}$ BPM with interfaces $(0)$ the spex $)$ piece and liner. 


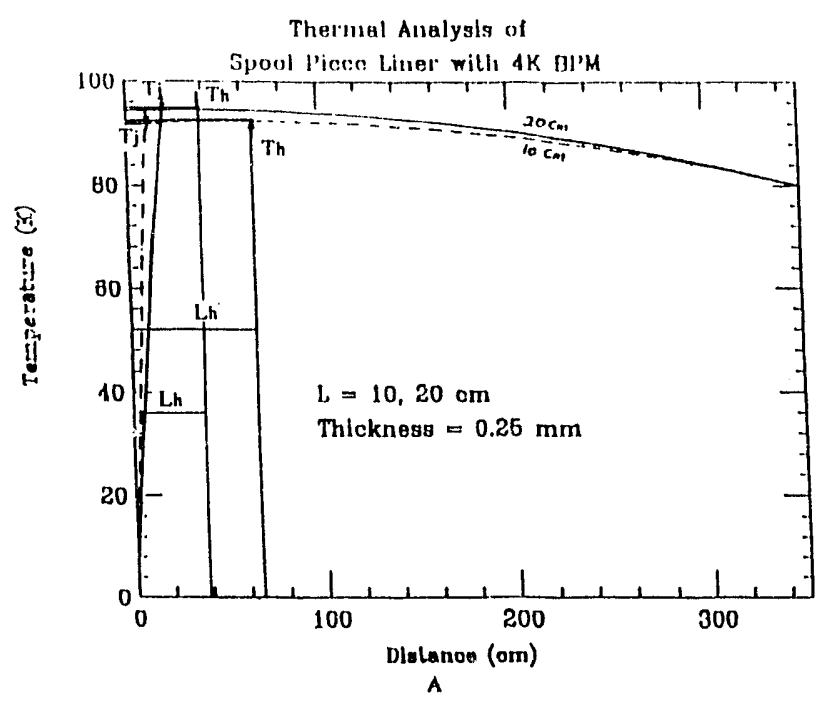

Figure 7. The temperature distribution als:"g an $80 \mathrm{~K}$ end-cooling spool piece liner with a $4 \mathrm{~K}$ BPM.

\section{LINER HEAT LOAD BUDGET AND IMPACT ON EXISTING SYSTEM}

In order to be of any positive cryogenic value, the liner must represent a smaller heat load to the $4 \mathrm{~K}$ refrigeration system than the synchrotron radiation does. The static heat load budget of the liner has thus been set at $1 \mathrm{~W}$ per dipole. Contributing heat loads arise from conduction through mechanical supports, blackbody radiation, end conduction through interconnect pieces, and conduction through the BPM. Details of the static $4 \mathrm{~K}$ heat budget are shown in Table $4 .{ }^{9}$

Table 4. Liner heat load budget (All units in $\bar{w}$ ).

\begin{tabular}{llccc}
\hline & Dipole & Quadrupole & Spool & Half Cell \\
\hline Support & 0.50 & 0.50 & 0.30 & 3.30 \\
IR Radiation & 0.20 & 0.06 & 0.04 & 1.10 \\
Interconnects & 0.05 & 0.05 & 0.05 & 0.35 \\
BPM & - & - & 0.26 & 0.26 \\
Total & 0.75 & 0.61 & 0.73 & 5.01 \\
\hline
\end{tabular}

\section{LOWER TEMPERATURE LINERS}

More than eight concepts for $4.2 \mathrm{~K}$ and $20 \mathrm{~K}$ liners have been studied as a result of the new photodesorption tests. ${ }^{14}$ Concept $\mathrm{A}$ has a sheet-metal (or extruded) shape with four supporting contacts to the $4 \mathrm{~K}$ beam tube integral to the liner tube. (see Figure 8 ). Concept B shows a circular beam tube with two brazed, hat-shaped supports running the full length of the tube (to ensure even thermal distribution between liner and bore tube). Both concepts would be optimized for good thermal contact between the liner and beam tube. In each concept, the cryosorber is located on the liner outer surface. The $20 \mathrm{~K}$ liner system concept is very similar to the $80 \mathrm{~K}$ system, but with the option of the cryosorber on the liner outer surface. Detailed information on the $20 \mathrm{~K}$ and/or $4 \mathrm{~K}$ liner will be published in other reports. 


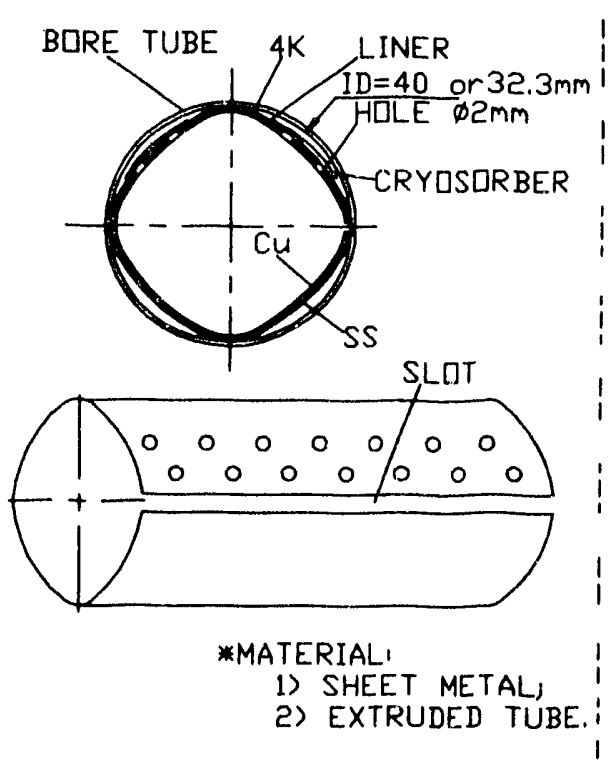

A
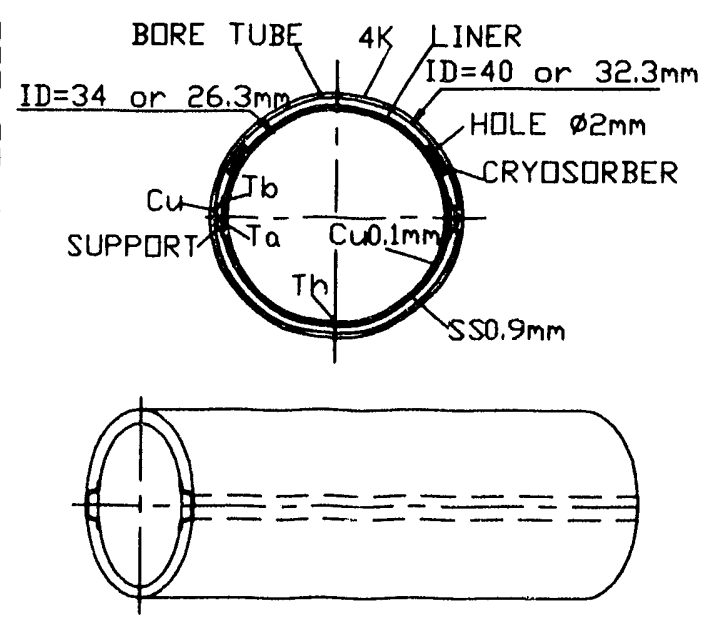

B

Figure 8. Two options for the $4 \mathrm{~K}$ liner.

\section{VERIFICATION AND DEMONSTRATION EXPERIMENTS}

Eight engineering experiments have been conducted or are planned to perform the design verification and concept demonstratio .. The following are brief summaries of their status:

1. The experiment of heat leak through liner supports has been conducted, and the results support the design concept.

2. The test on the good thermal conducting joint has been carried out. The preliminary results agree with the design analysis.

3. The equipment for the quench survivability test of a liner tube with supports is under construction. The test is planned to be performed at the SSCL Magnet Evaluation Lab.

4. The magnetoresistance of the combined liner tubes at $80 \mathrm{~K}$ has been tested at the SSCL Magnet Evaluation Lab.

5. The experiments on cryosorber will be developed and tested through vendors by contract.

6. The measurement of liner impedance with different perforated hole size and distribution patterns has been planned and started.

7. The RF surface resistivity of the liner tube at low temperature will be tested by Los Alamos National Lab for the SSCL. In addition, the RF surface resistivity of the liner tube at low temperature under high magnetic field will be tested with LANL, but at the SSCL Magnet Evaluation Lab.

8. $80 \mathrm{~K}$ liner system test at the ASS'T. This cryogenic test of the entire $80 \mathrm{~K}$ liner system will involve an entire Collider half-cell. The liner vacuum performance, crysorber performance, RF impedance, liner thermal performance, cryo-cooling loop, heat leak through supports, quench survivability, and liner alignment will be validated.

\section{DISCUSSION}

Design of an 80K ASST liner has been successfully accomplished. The trade studies, physics and enginecring analyses, conceptual design developments, detailed engineering design, and results from several experiments are briefly summarized in the design report as well as in the associated technical papers. ${ }^{4}$ 
It is recognized that this $80 \mathrm{~K}$ liner design development can not only be used for fabricating and testing of an $80 \mathrm{~K}$ Liner, but can also serve as a solid foundation for developing the lower temperature liner (i.e., $20 \mathrm{~K}$ or $4 \mathrm{~K}$ liners). All of the logic, the trade studies, the analyses, and the design work will be very useful references when a lowertemperature liner is pursued as a method to resolve the concern associated witt the synchrotron radiation and the consequential photodesorbed gases.

\section{REFERENCES}

1. H. Idwards, Study on Beam Tube Vacuum with Consideration of Synchrotron light, Potential Liner Intercept and Collider Quad/Spool (coil Diameter, SSCN-N-771, August 1991.

2. G. Dugan, SSCL internal memo on formation of the I iner R \& D task force, 9/4/92; W. Turner, SSCL internal memo on the ASST I iner I esign Team, 5/28/92.

3. W. Turner, SSC Vacuum Requirement, I'roton Collider Vacuum Technical Meeting, SSC.I., Dallas, TX, November 13, 1992;

D. Bintinger, P. Limon et al., Status of the SSC Photodesorption Experiment, SSC-102, December 1986; Site Specific Conceptual Design, SSC-SR-1056, July 1990.

4. (j. S. Shu, Report on the ASST II L.iner Status, SSCI.-N-805, November 1992;

Q. S. Shu, Design Report on SSC 80K Synchrotron Radiation Liner, SSCL.-N-818, July 1993.

5. Q. S. Shu, Liner System Design Minutes, SSCI. August 26, 1992.

6. Q. S. Shu, Liner System Design Minutes, SSCL. September 3, 1992.

7. D. Martin, Beam Position Monitor, Proton Collider Vacuum Technical Mecting, SSCL, Dallas, TX, November 1992.

8. W. Chou, Collider Vacuum Technical Meeting, SSCI, Dallas, TX, November 13, 1992;

S. Kurennoy et al., Liner Impedance Calculation and Beam Stability, Proton Collider Vacuum Technical Meeting, SSCL, Dallas, TX, November 13, 1992.

9. J. Maddocks, W. Chou, Collider Vacuum Technical Meeting, SSCI, Dallas, TX, November 13, 1992.

10. W. (.lay, (i. Morale, Interconnect Concept Design and Analysis, Internal Technical Review of the 80K ASST Liner Design, Dallas, TX, April 29-30. 1993

11. D. Martin, BPM System Concept Design and Analyses, Internal Technical Review of the 80K ASST Liner Design, Dallas, TX, April 29-30, 1993.

12. D. Clark, Spool Piece Liner Concept Design and Analyses, Internal Technical Review of the $80 \mathrm{~K}$ ASST Liner Design, Dallas, TX, April 29-30, 1993.

13. G. Morales, C. Murray, Liner Components and Assembly Detailed Design, Internal Technical Review of the 80K ASS: Liner Design, Dallas, TX, April 29-30, 1993.

14. Q. S. Shu et al., Several Options for the $4 \mathrm{~K}$ Liner Design, presented at the SSC: Collider Vacuum meeting, Dallas, IX, May 25, 1993. 

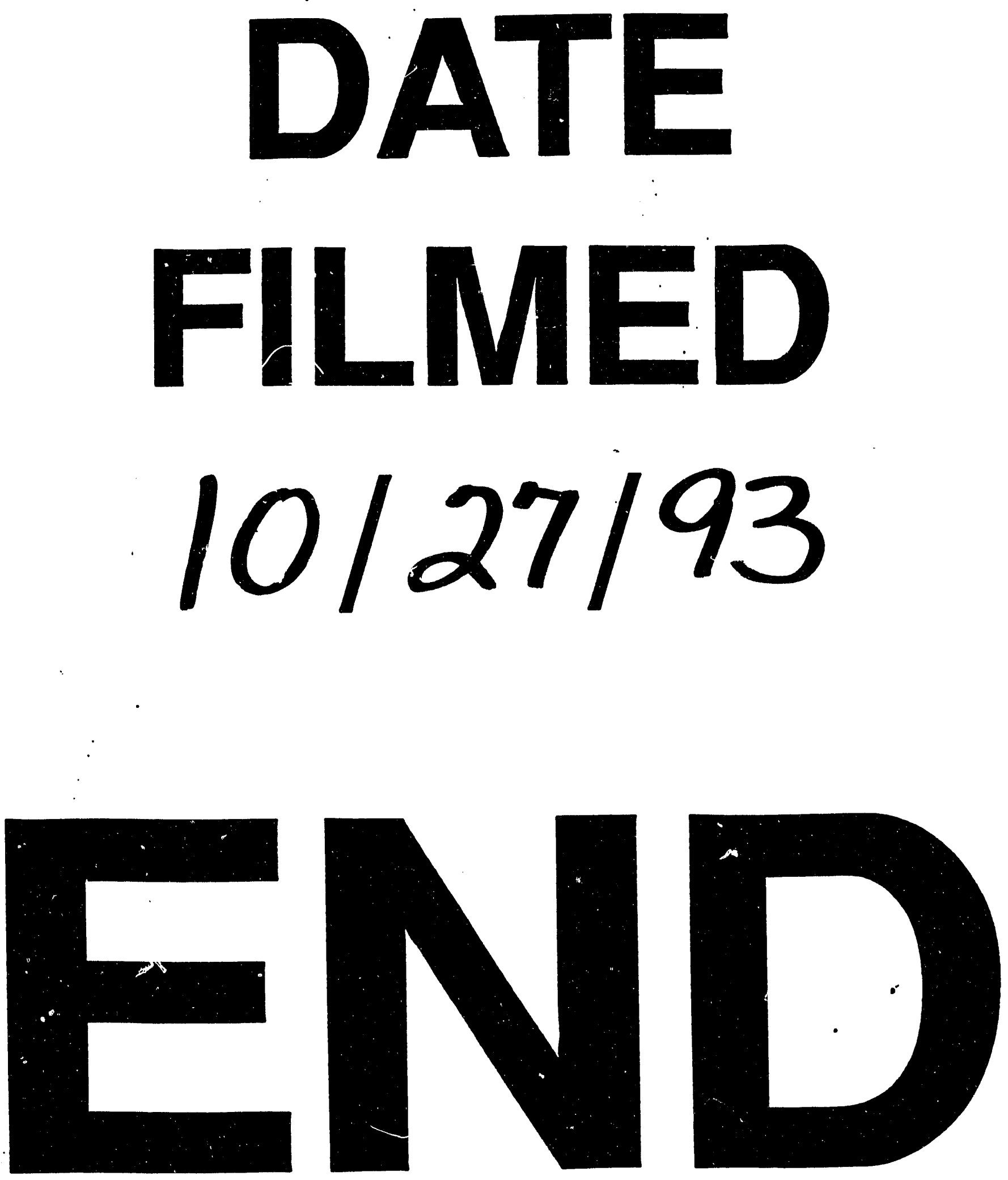
